\title{
Additive manufacturing - driving massive disruptive change in supply chain management
}

\author{
Klaus-Jürgen Meier \\ University of Applied Sciences Munich, Munich, Germany
}

\begin{abstract}
Purpose - There are many academic contributions dealing with the impact of additive manufacturing on supply chains (Ben-Ner and Siemsen, 2017; Durach, 2017; Gravier and Roethlein, 2018; Brown, 2018; Rogers et al., 2016; Sasson and Johnson, 2016; Nyman and Sarlin, 2014). But how future supply chain design may differ from today is still vague. In this article, possible scenarios are discussed and decision support is provided for the management, which is responsible for long-term strategic decisions.

Design/methodology/approach - This papers introduces the general characteristics of additive manufacturing and its next steps of development. Based on these technological assumptions various scenarios are systematically derived applying the standardized nomenclature of SCOR-model. Resulting threats and chances will be discussed and finally brought to a conclusion.

Findings - With the spread of additive manufacturing, the industry has the opportunity to pursue completely new approaches in terms of product development, design and product properties. This not only leads to new competitive models and the possibility of customer individualization of the products down to volume " 1 ". In addition, there are new models for supply chain management that can be used to react quickly and flexibly to customer requests. Already today new approaches for the cooperation between partners play an essential role.For start-ups, market entry should be simplified by using the resulting opportunities.

Research limitations/implications - Future developments and especially the development speed of additive manufacturing are not predictable. Therefore, the expected scenarios may differ from reality and lead to a different supply chain design. There will also be industries that can use additive manufacturing much more intensively than others - not least because of the technological restrictions of the manufacturing process. Corporate culture and the overcoming of technical challenges are a decisive factor.

Practical implications - This paper gives supply chain management an outlook on future development opportunities. This enables management to set the right course for a future-oriented position today.

Social implications - The changes in the supply chain will open up new business models while existing models will disappear. This leads to a change in the field of logistics but also for many technology providers. As a consequence, there will be serious changes (opportunities and risks) for the employees involved and their working environment.

Originality/value - This paper enables management to understand the scope and impact of upcoming changes. In this way, it significantly promotes awareness-raising and contributes to the future-oriented proceeding of companies.
\end{abstract}

Keywords Additive manufacturing, Supply chain management, 3D printing, Supply chain design, Disruptive change

Paper type Viewpoint

\section{Introduction}

Additive manufacturing is not new. Since the late 1980s, several companies have developed a manufacturing process that is not based on working out a component from a solid block, but rather building it up, layer by layer, in the shape of the contour that later forms its shape.

(C) Klaus-Jürgen Meier. Published in Journal of Work-Applied Management. Published by Emerald Publishing Limited. This article is published under the Creative Commons Attribution (CC BY 4.0) licence. Anyone may reproduce, distribute, translate and create derivative works of this article (for both commercial and non-commercial purposes), subject to full attribution to the original publication and authors. The full terms of this licence may be seen at http://creativecommons.org/licences/by/4.0/ legalcode
Additive manufacturing

Received 22 May 2020 Revised 26 May 2020 Accepted 28 May 2020 
JWAM

12,2

The manufacturing process fits into the modern zeitgeist. There is no waste of high proportions of material in the form of chips anymore (Nyman and Sarlin, 2014). Only just as much raw material is used as the component volume requires. Thus, this innovative technology is incorporated into the existing methods of the original molding techniques, such as casting. The big advantage of additive manufacturing, however, is that no molds and cores are needed, which make the prototyping economical only for larger quantities so far. Additive manufacturing is already working economically with a batch size of one. The only requirement is a file in STL format - comparable to a pixel file - which contains all printing information in layers. The innovative process meets the requirements of many customers in times of increasing digitalization: always customized and globally available (Ben-Ner and Siemsen, 2017).

No wonder, that additive manufacturing is predicted to have a great future. But will it revolutionize the future in the production plants or is it simply a new, further process beside the conventional chipping and chipless processes? Much will depend on the technical and procedural developments. And still more interesting, how will additive manufacturing change cooperation, business models and global footprint of firms in industry and commerce?

\section{Characteristics of additive manufacturing}

Plastic, metals, concrete or even food - additive manufacturing has opened a variety of raw materials (Gebhardt and Hötter, 2016). As a result, there are already applications in different industries such as home construction, mechanical engineering or automotive industry (Hofmann and Oettmeier, 2019). However, the production process not only allows the individualization of the quantities with well-known construction methods. The great potential only becomes clear when realizing the new design possibilities that additive manufacturing offers. Thus, for example, undercuts, honeycomb structures or geometries can be produced, which lead to more rigidity and lower weight at the same time (Brown, 2018). The encapsulation of electronic printed conductors and entire printed circuit boards in the printing process allow electronics and mechanics to merge. Moreover, components do not have to be assembled to the system or even to the finished product with a high effort but can be produced and assembled in one final process step. This also makes customer-specific adjustments in a serial process feasible, since with a modular product design, only a neutral module has to be replaced by a module provided by the supplier. The result is, for example, shoes whose sole is specially adapted to the body dimensions of the future wearer (Gebhardt and Hötter, 2016; Brown, 2018). Hence, the know-how in product manufacturing is increasingly shifting into the development and design process. The manufacturing process gets standardized. 3D printers reproducibly carry out the process in the same quality anywhere in the world. Speed and execution accuracy only depend on the performance of the printers.

Nowadays the wide spread is restricted by still high operating times per unit. The smaller the thickness of layers in the printing process, the better the print quality which can be achieved, but the longer it takes to form the component. The consequence is, that additive manufacturing today almost exclusively applies to the production of small quantities. This is the case, for example, in prototype construction, toolmaking or in the manufacture of customer-specific products (Walter et al., 2004). However, the increasing printing speed is more and more expanding the application areas. Recent generations of printers start to compete with injection molding (Asche, 2018a, b; Hofmann, 2019; Ben-Ner and Siemsen, 2017). Considering that additive manufacturing was designated for decentralized organizations due to the characteristics described above, it becomes clear that even the mass production of products becomes feasible with $3 \mathrm{D}$ printing. If required, printing is carried out by different partners close to the customer or possibly by the customer himself. The Original Equipment Manufacturers (OEM) are able to focus on the further development of their products. 
Production is done by print shops. Former "economy of scales" turns out to be "economy of one" (Brown, 2018).

In addition to the printing speed, the surface quality today is a central problem in many applications. The layer thickness mentioned above and the reproducible resolution of the printer are crucial to how good geometries - in particular curves-can be approximated by the digital structures (e.g. so-called Stair Step Effect in $z$-direction) (Gebhardt and Hötter, 2016). In many cases porous surfaces show up as a further effect. On the one hand, they result from a merging of required physical support structures with the processed material during printing and, therefore, cannot be removed completely without residue after the production process. On the other hand, the achieved material density in the printing process is crucial (Asche, 2018a, b). In industrial use, therefore, an (integrated) postprocessing is widespread and without any alternative. This still represents a massive barrier that prevents the outsourcing of production processes to print service providers.

In addition to the criteria mentioned, component size also plays a role, since it has a significant influence on the printer's working space and thus on its dimensioning and investment. Increased requirements come to the design of guiding rails and the positioning accuracy of the print heads. The complexity here further increases if different materials are to be processed. In the simplest case, these could be differently colored plastics in order to achieve colorations of a component up to photorealistic effects. Such 3D printers are already available. The same applies to the realization of material combinations of metal, plastic, rubber, glass or ceramic during a printing process (Homsel, 2019; Sasson and Johnson, 2016).

In summary, it is apparent that the current performance of commercially available 3D printers already offers numerous new possibilities in product design and in the production and logistics processes. However, for a wide spread of the printing technology a number of further optimizations and innovations are still required. The participation of industry giants like, for example, IBM (with the recent patent application of a hologram 3D printer operating without the use of physical support structures) (Krämer, 2019) shows, that this development is still in its infancy, is far from over and there is generally great market potential. There is a justified hope that a whole series of technical problems will be solved or at least gets significantly better controlled in the foreseeable future. The currently falling prices of 3D printers in the private and industrial sectors will contribute to spreading the technology.

The target at the end of the development may be the production of any desired product without subsequent surface treatment (such as grinding, hardening, painting), without assembly processes (even with movably mounted parts and parts consisting of different raw materials) and with integrated electronics. It will be some time before this dream becomes reality. However, many of the technological prerequisites already exist today (Rogers et al., 2016). It is no longer a utopia that this dream could become true. The only question is at what speed will manufacturers be able to translate the innovations into the devices? Moreover, to what extent will the resulting business processes prevail in the business-to-business (B2B) as well as the business-end customer area? New business models and new processes in production and logistics will result (Sasson and Johnson, 2016; Durach, 2017), although some researchers still predict a long timeframe until realization (Rogers et al., 2016; Holweg, 2015).

\section{Digitalization in supply chain management}

The design of supply chains has followed the same overall aims for decades. The achievement of sales goals and thus of economic success is always closely linked to the goal of optimally fulfilling customer expectations in terms of highest delivery capability, highest delivery reliability and shortest delivery time with minimal costs (Slack et al., 2016). The inventory level is particularly important in terms of availability and cost. In contrast, the approaches of implementing these goals have expanded in recent years. While conventional methods of 
JWAM

12,2

224

supplier management and procurement in low-wage countries lead to an increasing percentage of global added value (= global sourcing), digital networking has become a new and strong alternative for work-applied management. IT takes on a central function for the execution of business processes and business relationships (Slack et al., 2016). In addition to the so-called horizontal networking, there must be a vertical networking in digitalization. (Bauernhansl et al., 2014) It links the different hierarchal levels of a company (for example the actor and sensor level, control level, production management level, manufacturing and execution level, company planning level) (acatech - German Academy of Science and Engineering, 2012). By overlaying the horizontal and vertical structures, a matrix emerges that supports or sometimes even demands decentralized decision-making and process structures. At the interfaces of the vertical and horizontal networks so-called cyber physical systems (CPS) take over the communication and decision-making. CPS are embedded systems. At the same time, they work as a communication interface between man and machine (Bauernhansl et al., 2014). The proportion of autonomous information and material flow within a company as well as across the supply chain will increase dramatically in the upcoming years as a result of the use of the aforementioned technical possibilities. Further technological drivers include cloud and big data solutions and the Smart Factory (Emmrich et al., 2015). A fundamental requirement will be the smooth exchange of data between the companies involved in a supply chain and among machines from different manufacturers. This can be done either through a cross-sector standardization of data and formats (McMillan et al., 2017) or through a progressive development of the internet of Things towards a Web 3.0 (=Semantic Web). Horizontal and vertical networking can only be established if the ability is created to communicate and to provide meaningful data about products, orders and other specifications in all phases of the life cycle and to all instances of the supply chain involved.

Figure 1 below shows the section of a supply chain starting with the Tier 1 supplier right up to the customer. The representation uses the terminology of the second hierarchical level from the SCOR model. The designations are summarized in Figure 2. On display is a production company which manufactures customer-specific products and delivers them directly to its customers. The required raw material is sourced on behalf of different suppliers. A stock hold usually does not exist or exists only for variant-neutral parts and assemblies.

The higher the proportion of standardized components in the assortment is, the greater is the tendency of stock keeping. The aim of many companies is to reduce procurement costs and / or getting decoupled from the supplier by purchasing an optimal order quantity. A short-term ability to deliver is desired.

Figure 1.

Supply chain for the procurement, production and distribution of customer-specific products (according to the SCOR model)
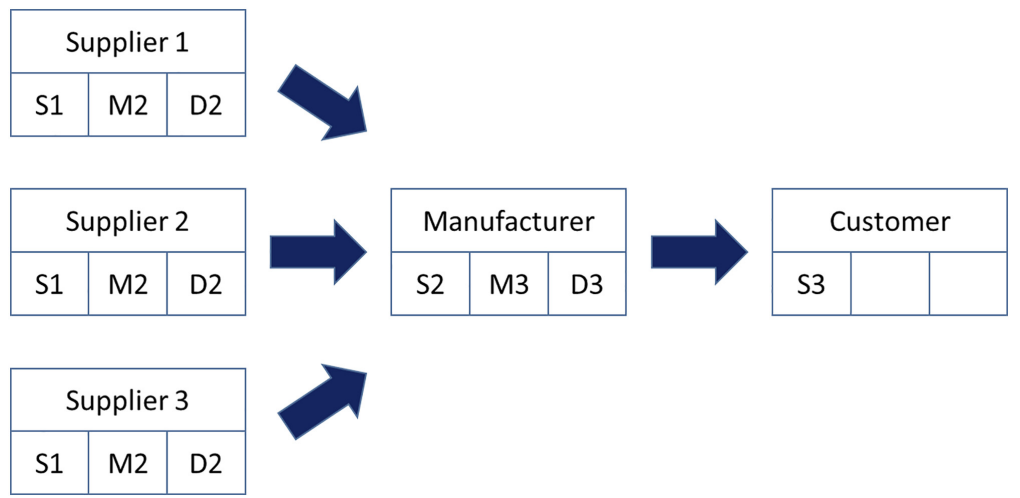
The influence of a pure digitalization is not visible on levels 1,2 and 3 of the SCOR model. It leads among others to accelerated processes, possibly automated and improved transparency along the entire supply chain (Bolstorff et al., 2007). For sure these are attractive benefits for work applied management. Decisions are more reliable or even rational for the first time. The planning and controlling should become easier for management. However, under the premise that today's existing business models are retained initially, the allocation of tasks among the participating companies does not change significantly. Resulting process changes due to the introduction of digitalization - as discussed above - only arise at the workflow level (Level 4). The process description on levels 1 to 3 according to Figure 1 remains untouched.

The introduction of digitalization often is said to bear the (disruptive) potential of new business models (Emmrich et al., 2015). These new business models tend to pursue the goal of no longer providing simple products but selling a value to the customers. For a machine building company, for example, this applies to machine running times, but not to the machine tool itself. Hence, engineering company pays for used machine hours and no longer invests in the acquisition of new machines and their maintenance during operation. The potential of such business models certainly exists. The supply chain as depicted in Figure 1 and the flow of materials and information remain largely unaffected. These business models only are affecting the ownership of assets and the responsibility to provide services for manufacturing and maintaining delivery ability.

\section{3D-printing in supply chain management}

In contrast to the effects of digitalization discussed so far, the spread of 3D printing is changing the supply chain (Hofmann, 2019) and work-applied management. The extent to which additive manufacturing alters the supply chain of Figure 1, however, crucially depends on the extent to which the technical challenges (see Chapter 2) are resolved (Sasson and Johnson, 2016). At the end of the development there may be even a dramatic change in business processes. This becomes clear when looking at Figure 3 below. Two alternative developments are shown:

It is noticeable at first glance that in both cases the process is significantly shorter and the number of companies involved has decreased. A disruptive change took place. The former manufacturer is no longer involved in the material flow. Instead of the physical product, he delivers a digital template to the customer (P3). In future, the present manufacturer is expected to have the task of concentrating completely on its core competence: the development and design of the products. Production as a core competence does not apply to him any longer. In alternative A (S1-M1-D1), customers manufacture all products in a 3Dprint by themselves. Few supplier (=retailers) ship all required raw material directly to the customer. Raw material for printers is standardized. Beside the print material, no further

stock has to be kept throughout the supply chain (Gravier and Roethlein, 2018). The required

\begin{tabular}{|c|c|c|c|c|c|c|c|}
\hline \multirow{3}{*}{\multicolumn{2}{|c|}{$\begin{array}{l}\text { Execution Processes: } \\
\text { 1: Stocked Product } \\
\text { 2: Make-to-Order Product } \\
\text { 3: Engineer-to-Order Product } \\
\text { 4: Retail Product }\end{array}$}} & & & & & & \\
\hline & & \multicolumn{5}{|c|}{ SCOR Process } & \\
\hline & & Plan & Source & Make & Deliver & Return & \\
\hline \multirow{3}{*}{$\begin{array}{c}\text { Process } \\
\text { Type }\end{array}$} & Planning & P1 & P2 & P3 & P4 & P5 & \multirow{3}{*}{$\begin{array}{l}\text { Process } \\
\text { Category }\end{array}$} \\
\hline & Execution & & S1 - S3 & $\mathrm{M} 1-\mathrm{M} 3$ & D1 - D4 & $\mathrm{R} 1-\mathrm{R} 3$ & \\
\hline & Enable & EP & ES & EM & ED & ER & \\
\hline
\end{tabular}

Figure 2. Summary of terminology according to the SCOR model, Level 2 (Bolstorff et al., 2007) 
JWAM

12,2

226

product information is electronically available to the customer at any time of day or night (Brown, 2018), enabling him to print his desired product as needed (M3). This eliminates long transport routes and transport times (Ben-Ner and Siemsen, 2017).

In alternative $\mathrm{B}$ the product is made by a print shop in the immediate vicinity of the customer. Customers commission print-shops after receiving the print file from the manufacturer. Print-shops schedule their required raw material stocks of printer material (S1) on their own. After printing the print-shop delivers the product (M3) to the customer on a short distance. Neither manufacturers nor customers are involved in the production process in alternative (B) In case of complex (product or production) structures service providers may support (Rogers et al., 2016).

The decision whether to implement alternative A or B depends largely on the complexity of the product and the resulting demands on the printing process. If this task occurs to the customer with a regularity, he will carry out the production processes inhouse. If, on the other hand, this is an exception (or even an isolated case), commissioning a print shop will be the economically better solution. Regardless of the decision (alternative A or B) all processes can be standardized despite the production of a customer-specific product. This testifies to the high potential of the solutions shown.

The effects of a developing additive manufacturing-technology (as in Figure 3) are discussed and derived on logical reflections always with regard to achieve savings as well as to reduce waste (according to lean philosophy) (Nyman and Sarlin, 2014) and effort for all participating members of a supply chain. Of course other researchers like Berman (2012), Rogers et al. (2016) and Khajavi et al. (2014) discussed this topic before. Though the results vary the remaining question is, whether end customers will be involved to fulfill the final production step on his own and thus, whether scenario A or B is likely to become true (Sasson and Johnson, 2016; Durach, 2017). Radical changes will take place anyway.

Apart from this discussion a prerequisite for the two described scenarios is the successful and complete coping with the following technical challenges (among others):

(1) production of finished products without assembly processes (or only to a limited extent);

(2) print of sliding or ball bearings;

(3) compliance with surface quality;

Figure 3.

Supply chain from

Figure 1 after introducing of a mature 3D printing technology. See also (Hofmann and Oettmeier, 2019; Heutger and Kückelhaus, 2019; Shafer, 2019) with high impact on workapplied management
Alternative A:
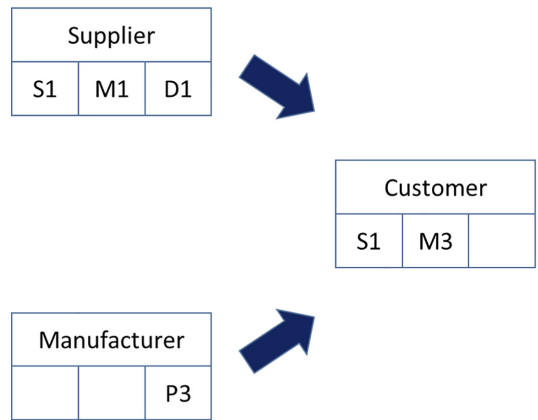

\section{Alternative B:}
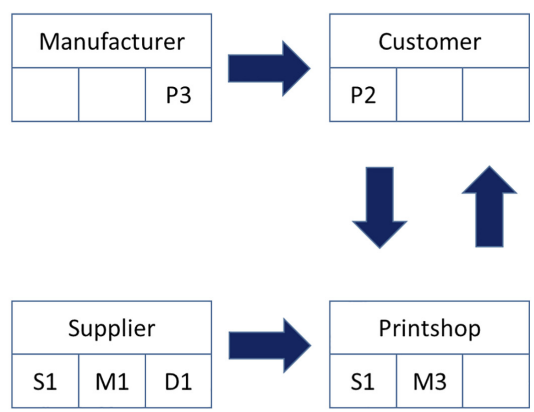
(4) compliance with positional and form tolerances;

Additive

(5) production of finished surfaces (including color design and creation of functional manufacturing surfaces) and

(6) printing of material combinations.

It will take some time until all these challenges are met. Also, the goals will not all be achieved at the same time and in the desired quality. The transition from the supply chain from Figure 1 to the supply chain depicted in Figure 3 will therefore not be done in one step. Rather, establishing one or more intermediate steps are unavoidable until 3D printing is able to substitute the full value adding of the manufacturer. Figures 4 and 5 below give an idea of what such an intermediate step might look like:

The evolutionary step in Figure 4 is likely to occur as long as the required technological challenges are not satisfactorily resolved yet. The manufacturer is in a position to produce its customer-specific products from a standard print material and to deliver them to the customer in accordance with the order (S1-M3-D3). Inventories and delivery times can be significantly reduced (Walter et al., 2004). However, the products must be post-processed using conventional production technology. To the extent conventional methods can be replaced, more and more value added steps can be shifted to subcontractors (see Figure 5). This constellation becomes particularly interesting when the process is pursued on a high quality level, but times per unit are still high and lead to long occupancy times on the printers. The supply chain shown in Figure 5 therefore is particularly applicable in mass or variety production. Large quantities are realized by using distributed capacities. Speed in this case is the decisive hurdle for starting the conversion of the supply chain according to Figure 1).

The supply chain processes shown in Figures 4 and 5 thus already represent a considerable simplification compared to the current proceeding (see Figure 1). With the current technological development of additive manufacturing, they can already be implemented in many applications. The process in Figure 3 requires numerous technical development goals to be achieved. In this case, the process enables a further significant simplification of the horizontal and vertical cooperation in a supply chain and thus also of

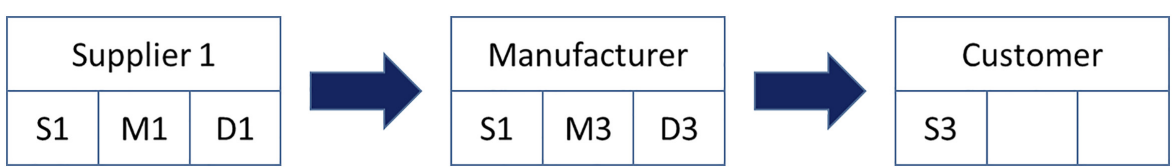

Figure 4.

Intermediate step on the development path of today's supply chain

to the economic and logistics optimum

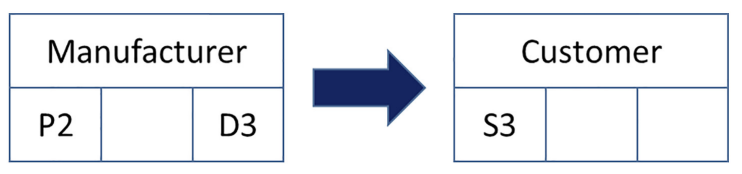

\begin{tabular}{|l|l|l|}
\hline \multicolumn{3}{|c|}{ Supplier 1} \\
\hline S1 & M1 & D1 \\
\hline
\end{tabular}

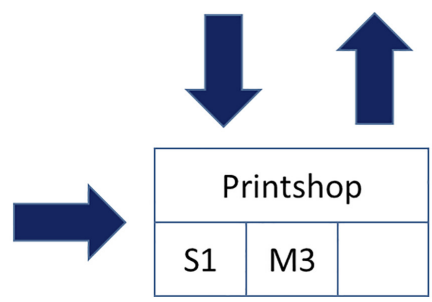

Figure 5.

Intermediate step on the development path of today's supply chain to the economic and logistical optimum with increasingly solved technical challenges 
JWAM

12,2 work-related management. It will then only be a matter of time before companies further adjust their supply chain processes to increase their competitiveness accordingly.

\section{Conclusion}

\subsection{Technological implications}

With the spread of additive manufacturing, the industry wins the opportunity to go for completely new ways in product development, design and product properties. This results in new competitive models and the opportunity for customer individualization of the products in lowest quantities. The widespread use still fails today due to technological problems that are relevant for some applications and also, in some cases, due to still too high production times. Today, however, production technology already has advantages in particular individual order production, such as prototype production. Dependent on the technological development of 3D printing, hybrid characteristics may arise until meeting the desired technological and industry-specific requirements. This means that products are processed using conventional molding processes and gain additional functions and properties through the use of additive processes. These functions and properties usually cannot be generated by conventional methods. Examples include honeycomb structures, undercuts or the embedding of electronics. Thus, additive manufacturing is already justified today and offers enormous potential for the foreseeable future (Rogers et al., 2016). Main issue is the implementation of new structures in supply chain management (Gravier and Roethlein, 2018). Current estimations state, that additive manufacturing already can help to get up to $20 \%$ of cost savings (Brown, 2018).

As prerequisites for this vision can be mentioned (see also (Heutger and Kückelhaus, 2019)):

(1) further overcoming the technical problems,

(2) standardization of technologies and data exchange formats for 3D printing,

(3) introduction of a payment system for print files,

(4) protection of print data and technical product know-how,

(5) legal certainty with regard to product liability issues,

(6) maintaining quality standards,

(7) clarification of the calculation basis for corporate tax, VAT and customs as well as,

(8) soft factors like "education of the engineers" or “customer awareness" (Durach, 2017),

(9) ability for smooth communication within supply chains (McMillan et al., 2017).

\subsection{Work-applied management implications}

In addition to product development, design and production engineering, the application of additive manufacturing also has significant effects on the supply chain and work-applied management. How far-reaching the consequences can be, is shown in Figure 1). The realization of the presented processes implies a radical change and a discontinuation of today's business models of many suppliers and logistics service providers. At the same time, new business models emerge, such as for printshops, which take over the production of the parts on behalf of their customers and in their immediate vicinity. Assemblies, transports and their times are eliminated and thereby accelerate the replacement. (Nyman and Sarlin, 2014) This makes it clear that the development will bring winners and losers.

The resulting migration path in the design of supply chains is summarized in Figure 6. 


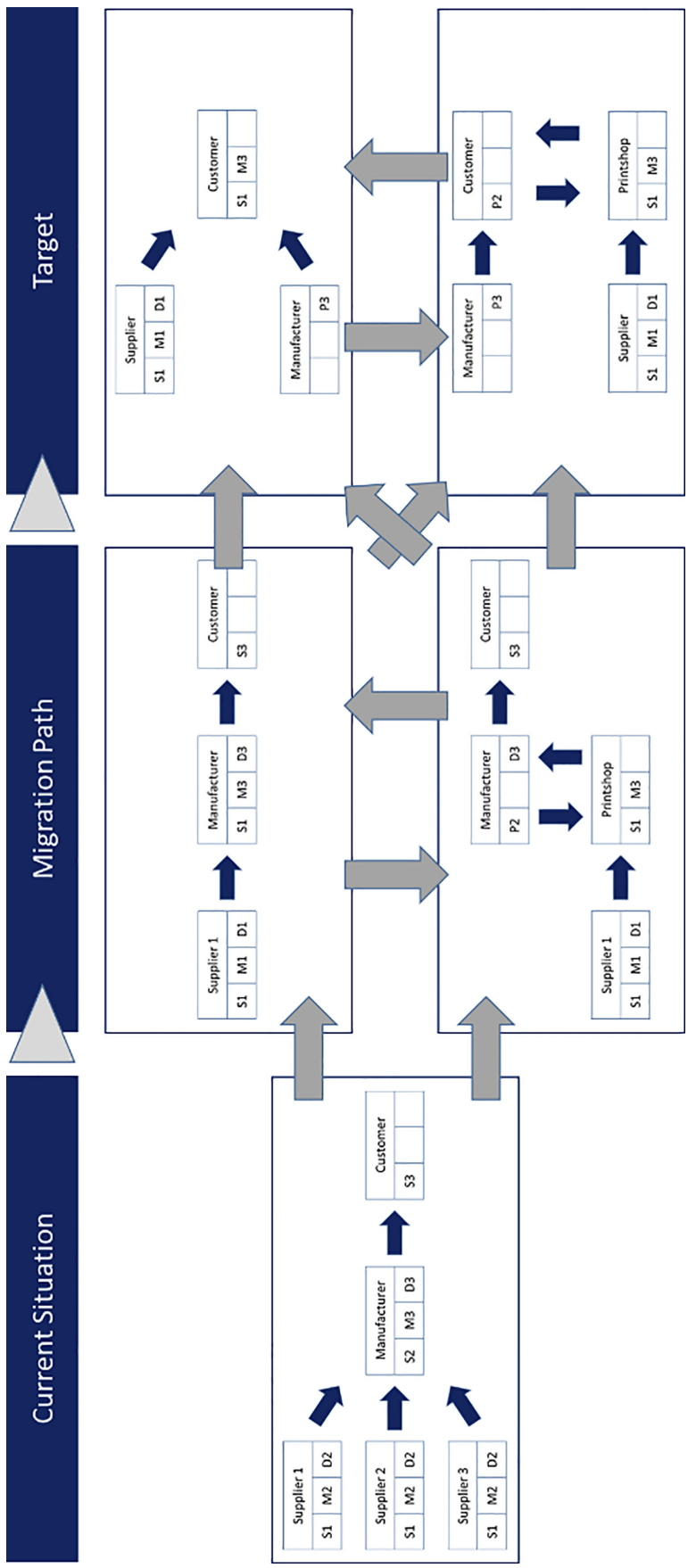

Additive manufacturing

229

Figure 6. Migration of supply chains under the influence of 3D printing. It results in the reduction and streamlining of supply chains and thus in a modification of workapplied management 
JWAM

12,2

The development of 3D printing performance always precedes changes in $\mathrm{SC}$ architecture. For this reason, the migration speed of the supply chain will significantly be linked to the sequence of technical developments in 3D printing. Hence 3D printing becomes an essential driver for the conversion and the speed of supply chain transformations (Sayer, 2019). Even if a single challenge turns out to be (still) insurmountable, others will be solved. The result is a continuous reduction and streamlining of the supply chain. Crucial for the management of supply chains and the work-related management of entire companies is to raise awareness of the expected developments and to include them in business decisions today. Current supply chains will face a massive disruptive change. (Berbain, 2017) Investment decisions and the collaboration agreement with partner companies should be made against the background of these upcoming changes. Companies that are now setting the right course will be among the winners of the paradigm shift. Right time for start-ups to jump into the market and to drive a massive change (Rogers et al.,2016) because a new organizational approach and less capital is needed (Ben-Ner and Siemsen, 2017). One may be curious as to whether and to what extent these developments only apply to the $\mathrm{B} 2 \mathrm{~B}$ sector or even include the end consumer (Durach, 2017).

\section{References}

acatech - German Academy of Science and Engineering (2012), Umsetzungsempfehlungen für das Zukunftsprojekt Industrie 4.0, available at: www.forschungsunion.de.

Asche, S. (2018a), "Ernste Konkurrenz für Spritzgießer”, VDI Nachrichten, Vol. 47, p. 17.

Asche, S. (2018b), "In einer neuen Gewichtsklasse”, VDI Nachrichten, Vols 49-50, p. 19.

Bauernhansl, T., ten Hompel, M. and Vogel-Heuser, B. (2014), Industrie 4.0 in Produktion, Automatisierung und Logistik, Springer, Wiesbaden.

Ben-Ner, A. and Siemsen, E. (2017), Decentralisation an Localization of Production: The Organizational and Economic Consequences of Additive Manufacturing (3D Printing), California Management Review, Vol. 59 No. 2, pp. 5-23.

Berbain, B. (2017), Designing the Additive Manufacturing Supply Chain, (S. 886-893), 2017 Annual Conference, Northeast Decision Sciences Institute, RI.

Berman, B. (2012), “3D printing: the new industrial revolution”, Business Horizons, Vol. 55, pp. 155-162.

Bolstorff, P.A., Rosenbaum, R.G. and Poluha, R.G. (2007), Spitzenleistungen im Supply Chain Management, Springer, Berlin Heidelberg NY.

Brown, A.S. (2018), "Chain reaction”, Mechanical Engineering, Vol. 140 No. 10, pp. 30-35.

Durach, C., Kurpjuweit, S. and Wagner, S. (2017), "The impact of additive manufacturing on supply chains", International Journal of Physical Distribution \& Logistics Management, Vol. 47, pp. 954-971, doi: 10.1108/IJPDLM-11-2016-0332.

Emmrich, V., Bauernhansl, T., Döbele, M., Paulus-Rohmer, D., Schatz, A. and Weskamp, M. (2015), Geschäftsmodell-innovation durch Industrie 4.0, Dr. Wieselhuber \& Partner GmbH, München.

Gebhardt, A. and Hötter, J.S. (2016), Additive Manufacturing, Carl Hanser, Munich.

Gravier, M.J. and Roethlein, C.J. (2018), "Putting traditional supply chains out of business: the disruptive impact of additive manufacturing", 2018 Annual Conference, Northeast Decision Sciences Institute, Providence, RI, pp. 695-715.

Heutger, M. and Kückelhaus, M. (2019), Innovation, D.C. (Ed.), 3D PRINTING and the FUTURE of SUPPLY CHAINS: DHL.Com, (accessed 16 February 2019).

Hofmann, E. and Oettmeier, K. (2019), Researchgate, from 3D-Druck: Wie additive Fertigungsverfahren die Wirtschaft und deren Supply Chains revolutionieren, available at: www.researchgate.net/ publication/304254229_3D-Druck_Wie_additive_Fertigungsverfahren_die_Wirtschaft_und_deren _Supply_Chains_revolutionieren. 
Hofmann, S. (2019), MM Logistik, from 5 Gründe, warum 3D-Druck die Logistik revolutionieren wird, available at: www.mm-logistik.vogel.de/5-gruende-warum-3d-druck-die-logistik-revolutionierenwird-a-735886/.

Holweg, M. (2015), “The limits of 3D printing”, available at: https:/hbr.org/2015/06/the-limits-of-3dprinting.

Homsel, G. (2019), 3D-Drucker verarbeiten mehrere Materialien in einem Durchgang, from Heise Online, available at: https://www.heise.de/newsticker/meldung/3D-Drucker-verarbeiten-mehrereMaterialien-in-einem-Durchgang-4029711.html.

Khajavi, S.P. (2014), "Additive manufacturing in the spare parts suply chain”, Computers in Industry, No 3, pp. 268-282.

McMillan, A., Swindells, N., Archer, E., Mcllhagger, A., Sung, A., Leong, K. and Jones, R. (2017), “A review of composite product data interoperability and product life-cycle management challenges in the composites industry", Advanced Manufacturing: Polymer \& Composites Science, Vol. 3 No. 4, pp. 130-147.

Nyman, H.J. and Sarlin, P. (2014), "From bits to atoms: 3D printing in the context of supply chain strategies", (S. 4190-4199), Hawaï International Conference on System Science, HI.

Rogers, H., Baricz, N. and Pawar, K.S. (2016), "3D printing services: classification, supply chain implications and research agenda", International Journal of Physical Distribution \& Logistics Management, Vol. 46 No. 10, pp. 886-907, doi: 10.1108/IJPDLM-07-2016-0210.

Sasson, A. and Johnson, J.C. (2016), “The 3D printing order: variability, supercenters and supply chain reconfigurations", International Journal of Physical Distribution and Logistics Management, No. 1, pp. 82-94.

Sayer, P. (2019), CIO, from How 3D Printing Can Affect Your Supply Chain, available at: www.cio.com/ article/3269256/supply-chain-management/how-3d-printing-can-affect-your-supply-chain.html.

Shafer, J. (2019), Inbound Logistics, from what Effect Will 3D Printing Have on Logistics and SCM?, available at: www.inboundlogistics.com/cms/article/what-effect-will-3d-printing-have-on-logisticsand-scm/.

Slack, N., Brandon-Jones, A. and Johnston, R. (2016), Operations Management, Pearson, Harlow.

Walter, M., Holmström, J. and Yrjölä, H. (2004), "Rapid manufacturing and its impact on supply chain management”, (S. 1-12), Logistics Research Network Annual Conference, Dublin, Ireland.

\section{Corresponding author}

Klaus-Jürgen Meier contacted at: klaus-juergen.meier@hm.edu

For instructions on how to order reprints of this article, please visit our website:

www.emeraldgrouppublishing.com/licensing/reprints.htm

Or contact us for further details: permissions@emeraldinsight.com 